\begin{tabular}{|c|c|c|}
\hline \multirow[t]{2}{*}{7} & $\begin{array}{l}\text { International Journal of Current Research in } \\
\text { Biosciences and Plant Biology }\end{array}$ & \\
\hline & Volume $4 \bullet$ Number 8 (August-2017) • ISSN: 2349-8080 (Online) & \\
\hline $\begin{array}{l}\text { EXCELLENT } \\
\text { PUBLISHERS }\end{array}$ & Journal homepage: www.ijcrbp.com & 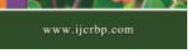 \\
\hline
\end{tabular}

\title{
Current Status of Milk Adulteration in Local Vendors of Milk, Lucknow Region of Uttar Pradesh, India
}

\author{
Amit Kumar Singh ${ }^{1}$ and Uma Shankar ${ }^{2 *}$ \\ I \& 2 Department of Microbiology/Life Sciences, Singhania University, Jhunjhunu-333 515, Rajasthan, India \\ *Corresponding author; ${ }^{1}$ Research Scholar.
}

\begin{tabular}{|c|c|}
\hline Abstract & Article Info \\
\hline \multirow{6}{*}{$\begin{array}{l}\text { The milk is high food value and its supplies nutrients like proteins, fat, carbohydrates, } \\
\text { vitamins and minerals. Due to nutritive value of milk is significant for human being. On } \\
\text { the other hand, milk is most commercially sold commodity both by local vendor's as well } \\
\text { as super markets. According to FSSAI, the most branded of products follow appropriate } \\
\text { quality in the marketed products. However in local products to increase the yield certain } \\
\text { adulterants are added which may affect the nutritional quality of milk. Therefore, the } \\
\text { present study aimed to expressive adulteration in different localities of vendors was Milk } \\
\text { product available. The adulteration observed mostly in milk product such as curd, and } \\
\text { buttermilk, butter and ghee were adulterated with vendors in most of milk and curd the } \\
\text { water content is more, but in few samples of urea and starch was also observed. The result }\end{array}$} & $\begin{array}{l}\text { Accepted: } 29 \text { July } 2017 \\
\text { Available Online: O6August } 2017\end{array}$ \\
\hline & Keywords \\
\hline & Adulteration \\
\hline & Milk quality \\
\hline & Milk products \\
\hline & \\
\hline
\end{tabular}

\section{Introduction}

Milk is a necessary product for good source of protein and also of calcium and riboflavin besides other nutrients (Singuluri and Sukumaran, 2014). The composition of milk varies significantly with the breed of cow, stage of lactation, feed, season of the year, and many other factors. However, some relationships between constituents are very stable and can be used to indicate whether any tampering with the milk composition has occurred (Ali et al., 2011; Kandpal et al., 2012; Tipu et al., 2007). A national study in India has uncovered that very nearly $70 \%$ of the milk sold and consumed in India is adulterated by contaminants such as detergent and skim milk powder, but impure water is the highest contaminant. As indicated by National
Survey on Milk Adulteration led by FSSAI (India) in 2011, water is the most widely recognized adulterant took after by cleanser in milk. A survey by FSSAI in $2012,68 \%$ milk samples was found to be adulterated in which $31 \%$ were from rural areas. Of these $16.7 \%$ were packet or branded milk and rest were loose milk samples from dairies. In the urban areas, $68.9 \%$ milk was found to be adulterated with water, detergent, urea and skim milk powder. In Uttarakhand, $88 \%$ milk was found to be adulterated. Despite the laws governing the quality and sale of milk existing in India for decades, the adulteration of milk has not been checked completely (Nirwal et al., 2013).

In order to keep milk temporarily fresh, some unethical activities are usually adapted to prevent the financial 
losses due to the spoilage of milk during its transportation and sale For instance, the addition of water to increase volume of milk, thickening agents like starch, flour, skimmed milk powder, whey powder or other ingredients to counter the dilution and extend the solids content of the milk. Vegetable oil, sugarcane or urea to compensate the fat, carbohydrate or protein content of diluted milk. Some chemicals such as hydrogen peroxide, carbonates, bicarbonates, antibiotics, caustic soda and even the most lethal chemical formalin to increase the storage period of milk, ice to enhance the shelf life of milk; detergents to enhance the cosmetic nature of milk which diminishes foamy appearance and whitening of milk or calcium thioglycolate/ potassium thioglycolate/ calcium salts of thioglycolic acid and urea for whitening of milk and giving it a genuine look (Soomro et al., 2014).

The adulteration of milk is banned due to the ill effects. Carbonate in milk produce gastrointestinal problems including gastric ulcer, diarrhoea, colon ulcer and electrolytes disturbance. The hydrogen peroxide disturbs the antioxidants in the body disturbing the natural immunity hence increasing aging. Chloride in themilk disturbs the acid base balance in the body and also blood $\mathrm{pH}$. Ammonia in milk develops regression, loss of acquired speech and sensory disturbances (Ayub et al., 2007) despite food legislation, adulteration remains uncontrolled, furthermore legal steps laid down in the PFA Act are extremely difficult to maintain due to inadequate and untrained man power and laboratory facilities (Monika and Gupta, 2008). Such is the state in the country where we are one of the largest nations of milk producers. In the year 2010-2011, India was ranked among the top 5 countries in the world producing 121.8 million tonnes of milk (FSSAI, 2016).

Food safety standards authority of India (FSSAI) conducted a survey in 2011 on milk adulteration in selected rural and urban areas, according to them the most common adulterant was found to be the addition of water, and the main reason for deviation from the standards was addition of glucose and skimmed milk powder. It also found that in some samples, detergent was mixed. Total of 1791 samples of milk were randomly collected from 33 states with a good mix of rural and urban areas as well as packaged and loose milk, after analysis 565 (31.5 per cent) samples were found to be conforming to the FSSAI standards whereas 1226 (68.4 per cent) samples of milk were found to be non-conforming (NDDB, 2016).

\section{Materials and methods}

\section{Survey method}

The local milk vendors of Lucknow region were chosen via random sampling method and approximate 50 samples from various vendors were collected in a sterilized container and subjected to laboratory techniques to determine the adulterants present in milk. The Samples were kept in a sterilized container in fridge at $4{ }^{\circ} \mathrm{C}$ which are analysed for adulteration properties which include (water test, urea test, starch test, detergent test).

Test: 5 adulteration tests were conducted to detect common adulterants in milk and milk product samples collected from various areas such as Baksi Ka Talab, Mahilahabad, Mohanlal Gang, Gosaiganj, Chinahat and Kursivillage samples were tests conducted are as follows:

Milk testing and quality control is an essential component of any milk processing industry. Milk being made up of $87 \%$ water is prone to adulteration by unscrupulous middleman and unfaithful farm workers. Moreover, its high nutritive value makes it an ideal medium for the rapid multiplication of bacteria, particularly under unhygienic production and storage at ambient temperature.

\section{Water test}

This test is used to check the presence of water in the milk sample. Due to the addition of water in the milk sample, it gets diluted. The extent of dilution depends upon the amount of water in the sample. Addition of water in milk can also dilute the nutrient content of milk and it also change the texture of milk. Water can be tested by pouring $1 \mathrm{ml}$ of milk on slide if milk fall easily than there is the presence of water in milk.

\section{Requirements: Slides}

Procedure: $1 \mathrm{ml}$ of sample was poured on slides; the movement of milk was observed.

\section{Urea test}

Urea is a natural constituent of milk and it forms a major part of the non-protein nitrogen of milk. Urea concentration in milk is variable within herd. Urea 
content in natural milk varies from $20 \mathrm{mg} / 100 \mathrm{ml}$ to 70 $\mathrm{mg} / 100 \mathrm{ml}$. However, urea content above $70 \mathrm{mg} / 100 \mathrm{ml}$ in milk indicates milk containing 'added urea'. The addition of urea to milk can be detected by using paradimethyl aminobenzaldehyde (DMAB). This method is based on the principle that urea forms a yellow complex with DMAB in a low acidic solution at room temperature.

\section{Requirements: Test tubes, Pipette, Tips}

Reagents: DMAB reagent $(1.6 \%, \mathrm{w} / \mathrm{v})$ : Dissolve $1.6 \mathrm{~g}$ DMAB in $100 \mathrm{ml}$ ethyl alcohol and add $10 \mathrm{ml}$ concentrated $\mathrm{HCl}$; milk samples.

Procedure: $1 \mathrm{ml}$ of milk sample was taken in a test tube; $1 \mathrm{ml}$ of $1.6 \%$ of DMAB solution was added to it. Observations were recorded.

\section{Starch test}

Starch test is used to check the presence of starch in milk. When iodine solution is added to milk sample, it reacts with starch present in milk and gives blue/black color due to formation of unstable starch ode compound.

\section{Requirements: Test tubes, Pipettes, Micro tips}

Reagents: Iodine solution, samples.

Procedure: $1 \mathrm{ml}$ of milk sample was taken in test tubes. Few drops of iodine solution were added to it. The change in color was observed.

\section{Ammonium compounds in milk}

This test is used to check the presence of ammonium compounds in milk. Nesseler's reagent is used for the detection of ammonium and ammonium salts At low concentration of ammonium compounds, brownish shade appears which is distinguishable at $0.15 \%$ followed by yellowish colour and then orange colour development at higher concentration.

\section{Requirements: Test tubes, Pipettes, Tips}

\section{Reagents: Nesseler's reagent, Samples}

Procedure: $2 \mathrm{ml}$ of sample was taken in a test tube; $2 \mathrm{ml}$ of nesseler's reagent was added to it; Color change was observed.

\section{Salt test}

The presence of extraneously added sodium chloride in milk can be detected by silver nitrate and potassium chromate reagent. Addition of salt in milk is mainly resorted to with the aim of increasing the corrected lactometer reading. Since sodium and chloride are two of the major ionic species in milk which undergo significant increase during lactation, hence the alcohol stability in milk is decreased.

\section{Requirements: Test tubes, Pipettes, Tips}

Reagents: $0.1 \%$ silver nitrate, Potassium chromate, samples.

Procedure: $2 \mathrm{ml}$ of sample was taken in a test tube. $5 \mathrm{ml}$ of silver nitrate was added to it followed by few drops of potassium chromate. Observation was recorded.

\section{Alcohol test}

The alcohol test is used on fresh milk to indicate whether it will coagulate on thermal processing. Milk with high developed acidity, or having calcium and magnesium compounds in greater than normal amounts, will coagulate when alcohol is added. Increased levels of albumen (colostrum milk) and salt concentrates (mastitis) may also results in a positive test.

Requirements: Test tubes, Pipettes, Tips

Reagents: $70 \%$ alcohol

Procedure: $1 \mathrm{ml}$ of milk ample was taken in a test tube. Around $2 \mathrm{ml}$ of $70 \%$ alcohol was added to it. Observation was recorded.

\section{Detergent test}

The milk that we drink might contain detergent. When we add some water in milk, we can see foam formation in milk sample. Drinking this kind of adulterated milk can lead to nausea, vomiting etc.

\section{Requirements: Test tubes, Pipettes, Tips}

Reagents: Distill water

Procedure: $5 \mathrm{ml}$ of milk sample was taken in a test tube. $10 \mathrm{ml}$ of distil water was added to it and sample was 
stirred properly. Observation was recorded.

\section{Neutralizer test}

Prohibited neutralizers like hydrated lime, sodium hydroxide, sodium carbonate or sodium bicarbonate are added to milk to prevent spoilage. The Rosalic solution is used for this test. If the colour of milk changes to pinkish red, it is inferred that the milk is adulterated with sodium carbonate / sodium bicarbonate and so unfit for human consumption.

\section{Requirements: Test tubes, Pipettes, Tips.}

Reagents: Rosalic solution

Procedure: $2 \mathrm{ml}$ of sample was taken in a test tube. $0.5 \mathrm{ml}$ of Rosalic solution was added to it. The change in color was observed.

\section{Results and discussion}

All the milk samples were analysed for adulteration test. The total eight tests were analysed, out of 50 samples 1 , 3,4 and 8 were showing same results in all the adulteration tests. were samples 2,5 and 9 were adulterated with water and starch similarly sample 6,7 and 10 were showing same results and they were adulterated with more amount of water and starch only sample 3 was differing from all the five samples as it was adulterated with water and detergent. Whereas, the remaining components were also found in some amount about 1 to 2 percentage in milk of the area of Malihabad region. The central region of Lucknow city, Hazaratganj the milk was highly mixed with neutralizer, urea and detergent (Fig. 1).

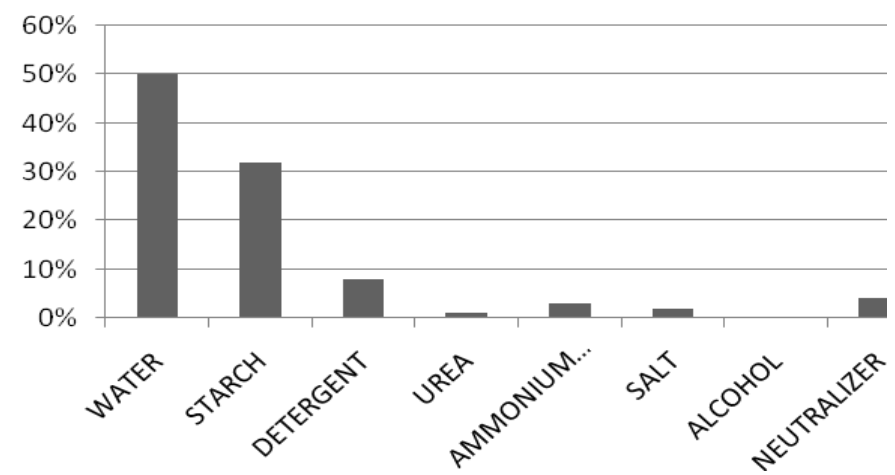

Fig. 1: Quality of milk samples analysed in the central region of Lucknow city, Hazaratganj.

From the above study its evident that the collected milk samples were adulterated with common adulterants like water, urea, detergent, ammonium compound salt, alcohol, neutralizer and starch, water being the most common adulterant, the milk samples collected were found containing excess water, starch and detergent, in the milk products like buttermilk and curd samples were found to be having not just excess water but also had added urea and detergent, the butter and ghee samples on other hand were loaded with all the four adulterants i.e. water, urea, starch and detergent. The different regions of Lucknow, the area of Chinahat is being supplied highly adulterated milk for the local milk venders followed by the Malihabad, Baksi Ka Talab and Gosaiganj regions of Lucknow. Thus it was found that all the so collected milk had varied proportions of common adulterants which might be detrimental risk to human health, therefore a governing body should periodically check these products for presence of these harmful ingredients.

\section{Conflict of interest statement}

Authors declare that they have no conflict of interest.

\section{References}

Ali, A., Mahmood, M.S., Hussain, L., Akhtar, M., 2011. Adulteration and microbiological quality of milk - A review. Pak. J. Nutr. 12, 1195-1202.

Ayub, M., Ahmad, Q., Abbas, M., Qazi, I.M., Khattak, I. A., 2007. Composition and adulteration analysis of milk samples. Sarhad J. Agric. 23(4), 1127-1130.

FSSAI, 2016. Food Safety and Standards authority of India. http://www.fssai.gov.in

Kandpal, S. D., Srivastava, A. K., Negi, K.S., 2012. Estimation of quality of raw milk (open and branded) by milk adulteration testing kit. Ind. J. Commun. Health. 3, 188-192.

Monika, G., Gupta, M. P., 2008. Recent Trends in Detection of Adulteration of Milk and Dairy Products. $8^{\text {th }}$ Edn. Dairy Book, Varanasi. pp.43-52.

NDDB, 2016. Department of Animal Husbandry, Dairying \& Fisheries, Ministry of Agriculture, GoI. Retrieved from National Dairy Development Board at: http://www.nddb.org/information/stats/milkprodindia

Nirwal, S., Pant, R., Rai, R., 2013. Analysis of milk quality, adulteration and mastitis in milk samples collected from different regions of Dehradun. Int. J. PharmTech. Res. 5(2), 359-364.

Singuluri, H., Sukumaran, M.K., 2014. Milk adulteration in Hyderabad, India - A comparative 
study on the levels of different adulterants present in milk. J. Chromatograph. Separat. Techniq. 5(1), 212.

Soomro, A. A., Khaskheli, M., Memon, M. A., 2014. Study on adulteration and composition of milk sold at badin. Int. J. Res. Appl. Natural Social Sci. 2(9),
57-70.

Tipu, M. S., Altaf, I., Ashfaq, M., Siddique, S., 2007. Monitoring of chemical adulterants and hygienic status of market milk. Handbook published by Quality Control Laboratory, Univ. Vet. Anim. Sci., Lahore, Pakistan. 7p.

\section{How to cite this article:}

Singh, A. K., Uma Shankar, 2017. Current status of milk adulteration in local vendors of milk, Lucknow region of Uttar Pradesh, India. Int. J. Curr. Res. Biosci. Plant Biol. 4(8), 111-115.

doi: https://doi.org/10.20546/ijcrbp.2017.408.015 